\title{
Frequencies of two CYP2C19 Defective Alleles (CYP2C19*2, and *3) among Iranian Population in Mazandaran Province
}

\author{
Naghi Shahabi-Majd ${ }^{1}$, Mohammad Bagher Hashemi-Soteh ${ }^{1}$, Baharak Habashi², Mohammad Reza Shiran ${ }^{2 *}$ \\ ${ }^{1}$ Molecular and Cell Biology Research Centre Faculty of Medicine, Mazandaran University of Medical Sciences, Sari, Iran. \\ ${ }^{2}$ Psychiatry and Behavioral Sciences Research Centrer of Medicine, Mazandaran University of Medical Sciences, Sari, Iran.
}

Received: 15 Nov 2012

Revised : 20 Feb 2013

Accepted: 5 Mar 2013

Corresponding Author:

Mohammad-Reza shiran

Psychiatry and Behavioral Sciences

Research Center, Faculty of Medicine,

Mazandaran University of Medical

Sciences, Sari, Iran

Postal Code: 48471-91971

Tel: +98-11 3543081-3

Email: mr.shiran@gmail.com

\begin{abstract}
Background: Cytochrome P450 2C19 (CYP2C19) is a polymorphically expressed enzyme that shows marked interindividual and interethnic variation. CYP2C19*2 and CYP2C19*3 are the most frequent identified defective alleles in Orientals and Caucasian poor metabolizers (PM). The aim of this study was to investigate the frequencies of CYP2C19*1, CYP2C19*2 and CYP2C19*3 alleles and CYP2C19 genotypes among Mazandarani ethnic group among Iranian Population.

Materials and Methods: The study was conducted on 103 unrelated healthy volunteers. DNA was extracted from leucocytes and analyzed by the PCR-RFLP protocol. The PCR product was digested with restriction enzymes (SmaI and BamH1) and then separated electrophoretically using polyacrylamide gel.

Results: Of the tested alleles, CYP2C19*1, and CYP2C19*2, but not CYP2C19*3, were detected. The frequencies for CYP2C19 alleles *1, $* 2$, and *3 were $91 \%, 9.0 \%$, and $0.0 \%$, respectively. CYP2C19 genotypes $* 1 / * 1, * 1 / 2$, $* 1 / * 3, * 2 / * 2, * 2 / * 3$ and $* 3 / * 3$ frequencies were $84 \%, 14 \%, 0.0 \%, 2.0 \%$, and $0.0 \%$, respectively.

Conclusion: The result of the present study shows that the two inactive alleles of CYP2C19 accounted for $9.0 \%$ of CYP2C19 alleles in our sample versus 8.8 $40.1 \%$ reported in other populations. The studied alleles frequencies was significant difference between our sample and African and Eastern Asian populations.
\end{abstract}

Keywords: CYP2C19; Genotype; Alleles; Mazandaran; Iranian

Please cite this article as: Shahabi-Majd N, Hashemi-Soteh MB, Habashi B, Shiran MR. Frequencies of two CYP2C19 Defective Alleles (CYP2C19*2, and *3) among Iranian Population in Mazandaran Province. Res Mol Med. 2013 ; 1 (1): 16-20

\section{Introduction}

Genetic polymorphisms of cytochrome P450 (CYP) enzymes in humans are the main cause of differences in the metabolic activities of therapeutic drugs (1-2). The major genetic polymorphisms affecting drug metabolizing enzymes activity of potential clinical relevance are those related to drug oxidation by CYP2D62C9and 2C19(3-4). CYP2C19 exhibits high genetic polymorphism (www.cypalleles.ki.se/cyp 2c19.htm), including two common defective variants Single-base substitutions in the coding sequence of CYP2C19*2 and CYP2C19*3 lead to splicing defect and premature stop codon, respectively. Therefore these substitutions can cause null function of the enzyme.There are significant ethnic differences in the frequency of these variants. CYP2C19*2 has been identified as the most common mutant allele of CYP2C19 among Caucasians and Filipinos, appearingin $9.1-39 \%$ of the population, respectively (5-9). CYP2C19*3 is common in Oriental population but extremely rare in Caucasians and among African populations (9). The prevalence of PMs was reported to be $2-5 \%$ in Caucasians $(8,10,11), 4-8 \%$ in Africans (11-12) and $11-23 \%$ in Orientals $(11,13,15)$.

Although the allele and genotype frequencies of CYP2C19 have been studied extensively in most populations world-wide, limited informations are available for those of the Iranian population (16-17). Here in, we examined the frequencies of 
CYP2C19*1, CYP2C19*2, and CYP2C19*3 alleles and CYP2C19 genotypes among Mazandarani ethnic group of Iranian Population.

\section{Materials and Methods \\ Subjects}

One hundred and three unrelated healthy volunteers of Mazandarani origin residing in Mazandaran, province in the north of Iran, were enrolled in the study. The study protocol was approved by the Research Ethics Committee of Mazandaran University of Medical Sciences. Written consent forms were given from all the subjects.

\section{Chemicals and drugs}

Magnesium chloride, ethylenediaminetetraacetic acid, Tris-hydrochloric acid, and sodium chloride were purchased from Merck Chemical Company. Restriction enzymes and primers were prepared by Fermentas. Ultra-pure water was obtained using a Milli-Q water purification system.

Determination of CYP2C19 genotype-Genomic DNA extraction and PCR amplification

A 10 milliliters venous blood was obtained from each subject and transferred into sterile plastic tubes containing Na-EDTA and stored at $-25^{\circ} \mathrm{C}$ until to be processed. Lymphocytic genomic DNA was isolated according to previously published method (18). The DNA samples were stored at $4{ }^{\circ} \mathrm{C}$. Allele-specific polymerase chain reaction was carried out to detect the CYP2C19*2, CYP2C19*3 alleles. The method of De Morais et al. $(6,19)$ was used to detect the CYP2C19*2 and for CYP2C19*3, respectively.

Briefly, a solution of $0.5 \mu \mathrm{l}$ of $100 \mathrm{ng} / \mu \mathrm{l}$ genomic DNA was pipetted into $0.2 \mathrm{ml}$ thin-walled PCR tubes. A master mix was prepared according to the number of samples to be genotyped. This comprised (per tube) $1 \mu 1$ of $20 \mu \mathrm{M}$ of each of the primers in Table 1 , $0.2 \mu \mathrm{l} \mathrm{Taq}{ }^{\circledR}$ DNA polymerase, $0.7 \mu \mathrm{l}$ of sterile water and $46.5 \mu$ l of 'Reddy mix' (75 mM Tris- $\mathrm{HCl} \mathrm{pH} 8.3$, $1.5 \mathrm{mM} \mathrm{MgCl} 2,0.2 \mathrm{mM}$ each of dATP, dCTP, dGTP and dTTP).

DNA samples were initially denatured at $94^{\circ \mathrm{C}}$ for 1 minute. DNA amplification was achieved by 35 cycles of denaturation $\left(95^{\circ} \mathrm{C}, 60 \mathrm{sec}\right)$, annealing for $60 \mathrm{sec}$ and extension $\left(72{ }^{\circ} \mathrm{C}, 60 \mathrm{sec}\right)$. Then, the samples were subjected to a final extension step in $72{ }^{\circ} \mathrm{C}$ for 5 min. Finally, a $169 \mathrm{bp}$, and $329 \mathrm{bp}$, PCR fragment were achieved forCYP2C19*2, CYP2C19*3 respectively. A $10 \mu \mathrm{l}$ of aliquot of each PCR product was run on a $10 \%$ polyacrylamide gel to check for positive amplification.

Restriction of amplified samples

Restricted enzyme digestion was carried out as recommended by the manufacture.

Table1. Sequences and Orientation of Primers Used in Polymerase Chain Reactions.

\begin{tabular}{llll}
\hline Alleles & \multicolumn{1}{c}{ Primers sequence } & Orientation & References \\
\hline CYP2C19*2 & 5'- AATTACAACCAGAGCTTGGC-3' & F & $(19)$ \\
& 5'- TATCACTTTCCATAAAAGCA-3 & $\mathrm{R}$ & \\
CYP2C19*3 & 5'- TATTATTATCTGTTAACTAA-3' & $\mathrm{F}$ & $(6)$ \\
& 5'- ACTTCAGGGCTTGGTCAATA -3 & $\mathrm{R}$ & \\
\hline
\end{tabular}

$\mathrm{f}=$ forward primer, $\mathrm{r}=$ reverse primer

$10 \mu 1$ of each CYP2C19*2, and CYP2C19*3 sample were digested using a mastermix of each enzyme (30 $\mu \mathrm{l}$ restriction enzyme $+200 \mu \mathrm{l}$ buffer, aliquot $50 \mu \mathrm{l}$ ) according to the manufacturer. A $2.3 \mu \mathrm{l}$ aliquot of each SmaI and BamH1 mastermix was added to $10 \mu \mathrm{l}$ of PCR product for each CYP2C19*2 and CYP2C19*3 samples, respectively. The reaction tubes were incubated for overnight at $37{ }^{\circ} \mathrm{C}$ prior to analysis on a $10 \%$ polyacrylamide gel. The gel was electrophoresed for $40 \mathrm{~min}$ at 200 volts in $1 \mathrm{XTBE}$ buffer and stained by $1 \mu \mathrm{g} / \mathrm{ml}$ ethidium bromide.

\section{Results}

One hundred and three subjects were genotyped. Examples of digestion reactions for detection of CYP2C19*2, and CYP2C19*3 alleles are shown in Figure 1.

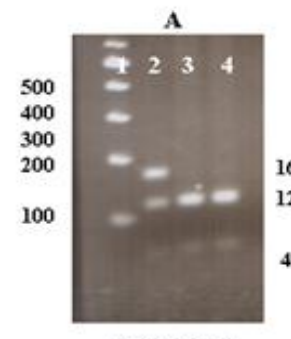

CYP2C19"2

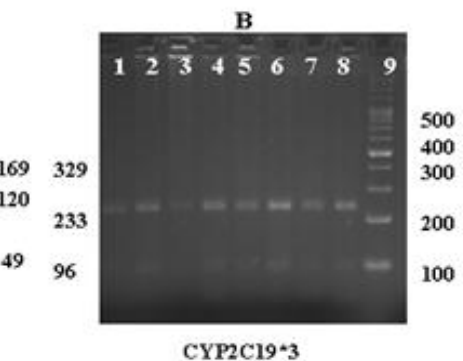

CYP2C19*3
Figure 1. Gel pictures after polymerase chain reaction-restriction fragment length polymorphism. A) CYP2C19*2; Lanes 1,100bp DNA marker, lane 2 heterozygous for $* 2$, lane 3 to 4 , wild-type individuals. B) CYP2C19* 3; lanes 1 to 8 , wild-type individuals, with 2 bands, 96 and 233 bp after 329 bp PCR product digestion with BamH1 restriction enzyme. Lane 9, 100bp DNA marker.

Of the alleles tested, CYP2C19*1, and CYP2C19*2, but not CYP2C19*3, were detected. The frequencies of the CYP2C19*1, and CYP2C19*2 alleles as well the genotype frequencies in the Mazandarani population are summarized in Table 2 .

The frequency of polymorphic CYP2C19*2 allele was $9 \%$ in our population. Whereas $84 \%$ of patients were extensive metabolizer (EM) (all homozygous for the CYP2C19*1 allele, (CYP2C19*1/*1), 14\% of subjects had a heterozygous intermediate metabolizer (IM) genotype (CYP2C19*1/*2). In $2 \%$ of subjects, a homozygous $(\mathrm{CYP} 2 \mathrm{C} 9 * 2 / * 2)$ PMs genotype was identified. 
Table2. Allele and genotype frequencies of CYP2C19 in Mazandarani ethnic group among Iranian Population $(\mathrm{n}=103)$.

\begin{tabular}{lcc}
\hline Variant allele & Allele frequency $(\%)$ & $\mathbf{9 5 \%}$ confidence interval \\
\hline CYP2C19*1 & 91 & $87.4-93.3$ \\
CYP2C19*2 & 9 & $7.6-12.5$ \\
CYP2C19*3 & 0 & -
\end{tabular}

\begin{tabular}{lcc} 
Genotype & Frequency (\%) & $\begin{array}{c}\text { Anticipated phenotype } \\
\text { (based on genotype) } \\
\text { (Homozygous-EM) }\end{array}$ \\
CYP2C19*1/CYP2C19* & 84 & (Heterozygous-IM) \\
CYP2C19*1/CYP2C19*2 & 14 & (Heterozygous-IM) \\
CYP2C19*1/CYP2C19*3 & 0 & (Homozygous -PM) \\
CYP2C19*2/CYP2C1 & 2 & (Homozygous -PM) \\
CYP2C19*3/CYP2C19* & 0 & metabolizer; IM, intermediate \\
\hline PM, poor & metabolizer; & EM,extensive
\end{tabular}
metabolizer.

\section{Discussion}

There are a number of ethnic groups living in various parts of Iran. These ethnic groups include Persian,
Azari, Turkmen, Kurd, Arab, Lor, Balouch, Gilaki and Mazandarani. Although CYP2C19 genetic polymorphisms have previously been assessed in a random Iranian population (16) and southern Iranians (17), there was no data in the Mazandarani ethnic group. The frequencies of the CYP2C19*2 alleles found in the Mazandarani ethnic group were very close to those found in Caucasian populations (9.1$15.9 \%)(5,7,20,24)$ (Table3).

By contrast, the CYP2C19*2 alleles occur at a significantly higher frequencies in the Asian and East Asian countries (14-39\%) (8, 9, 20, 25) (Table3).

CYP2C19*2 allele frequency occur at relatively high frequencies in the African and Afirican-Americans $(13-25 \%) \quad(7-9, \quad 20,26-29) \quad$ (Table3). While CYP2C19*3 alleles is absent among different populations with Caucasian background, Europeans, Canadians-Australians, European $(5,8,9,23,33,34)$, A frican and African-American populations $(7,9,26)$.

Table3. Allele and genotype frequencies of CYP2C19 in different population

\begin{tabular}{|c|c|c|c|c|c|c|c|c|c|c|c|}
\hline \multirow[t]{2}{*}{ Population } & \multirow[t]{2}{*}{ References } & \multirow[t]{2}{*}{$\mathbf{n}$} & \multicolumn{3}{|c|}{ Allele frequency $(\%)$} & \multirow[b]{2}{*}{$* 1 / *$} & \multirow[b]{2}{*}{$* 1 / * 2$} & \multicolumn{3}{|c|}{ Genotype frequency $(\%)$} & \multirow[b]{2}{*}{$* 3 / * 3$} \\
\hline & & & $* 1$ & $* 2$ & $* 3$ & & & $* 1 / * 3$ & $* 2 / * 2$ & $* 2 / * 3$ & \\
\hline \multicolumn{12}{|l|}{ Asians } \\
\hline Present study & Present study & 103 & 91 & 9 & 0 & 84 & 1 & 0 & 2 & 0 & 0 \\
\hline Iranian (random) & $(30)$ & 82 & 84.75 & 13.41 & 1.8 & 70.7 & 24.3 & 3.7 & 1.3 & 0 & 0 \\
\hline Iranian (southern) & (17) & 147 & 86.73 & 13 & 1 & 74.14 & 24.4 & 0.68 & 0 & 0.68 & 0 \\
\hline Iranian (random) & (16) & 200 & 86 & 14 & 0 & 75 & 22 & 0 & 3 & 0 & 0 \\
\hline Indian [31] & (25) & 230 & 67 & 33 & 0 & 46 & 42 & 0 & 0.1 & 0 & 0 \\
\hline Gaza Strip & (32) & 200 & 91.3 & 5.8 & 3 & 86.5 & 6. & 1.5 & 3 & 0.5 & 2 \\
\hline Tamilian & (20) & 112 & 59.8 & 37.9 & 2.2 & 29.5 & 58 & 2.7 & 8 & 1.8 & 0 \\
\hline North Indians & (20) & 121 & 70.3 & 29.7 & 0 & 47.9 & 44.6 & 0 & 7.4 & 0 & 0 \\
\hline Orientals* & (20) & 368 & 61 & 30.5 & 8.5 & 38.4 & 36.7 & 8.4 & 8.7 & 6.5 & 1 \\
\hline \multicolumn{12}{|l|}{ Caucasians } \\
\hline Russian & (24) & 290 & 88.2 & 11.4 & 0.3 & 78.7 & 19 & 0.3 & 1.7 & 0.3 & 0 \\
\hline Italian & (5) & 360 & 88.9 & 11.1 & 0 & 79.4 & 18.9 & 0 & 1.7 & 0 & 0 \\
\hline Greek & (5) & 283 & 87 & 13 & 0 & 75.97 & 21.91 & 0 & 2.21 & 0 & 0 \\
\hline Slovenian & (22) & 129 & 83.7 & 15.9 & 0.3 & 68.2 & 30 & 0.7 & 0. & 0 & 0 \\
\hline Croatian & (21) & 200 & 85 & 15 & 0 & 73 & 24 & 0 & 3 & 0 & 0 \\
\hline Belgian & (7) & 121 & 90.9 & 9.1 & 0 & 83.5 & 14.9 & 0 & 1.6 & 0 & 0 \\
\hline Caucasians** & (20) & 837 & 86 & 14 & 0 & 74.8 & 23 & 0 & 2.2 & 0 & 0 \\
\hline \multicolumn{12}{|l|}{ Africans } \\
\hline Beninese & (7) & 111 & 87 & 13 & 0 & 73.9 & 26.1 & 0 & 0 & 0 & 0 \\
\hline Egyptian & (27) & 247 & 88.8 & 11 & 0.002 & 78.56 & 20.24 & 0.40 & 0.80 & 0 & 0 \\
\hline Tanzanian & (26) & 195 & 90 & 10 & 0 & 82 & 16.4 & 0 & 1.5 & 0 & 0 \\
\hline Africans & $(20)$ & 251 & 81.4 & 17.9 & 0.7 & 66.1 & 29.8 & 0. & 2.7 & 0.4 & 0 \\
\hline
\end{tabular}

*(Japanese, Chinese, and Thais); ** (European Americans, Turks, Germans

The frequency of CYP2C19*3 found in Mazandarani ethnic group in this study was $(0 \%)$ similar to those showed in Caucasian, Africans and also previous reports from a random sample of Iranians (Table 3). By contrast, the CYP2C19*3 alleles occur at a relatively higher frequencies in the East Asian countries $(8,9,20)$ (Table 3 ).

The frequency of poor metabolizers of CYP2C19 found in the present study (2\%) was comparable to Caucasian populations $(2-5 \%)(8,10,11)$. Dissimilarity CYP2C19 PM frequency is higher in

Africans $(4-8 \%)(11,12)$ and in Orientals $(11-23 \%)$ $(11,13-15)$. In conclusion, the tested allelic variants of CYP2C19 existed in the Mazandarani ethnic group with frequencies are comparable to Caucasian populations with some differences among East Asians and Africans. It is hoped that our results will aid in understanding the ethnic diversity of the Iranian population, and offer a preliminary basis for more rational use of drugs that are substrates for CYP2C19 in this population.

\section{Acknowledgements}

This study has been supported by a grant from the research council of Mazandaran University of Medical Sciences.

Conflict of interest: None declared. 


\section{References}

1. Bertilsson L. Geographical/interracial differences in polymorphic drug oxidation.Current state of knowledge of cytochromes P450 (CYP) 2D6 and 2C19. Clin Pharmacokinet.1995; 29(3): 192-209. PMID: 8521680

2. Daly AK, Cholerton S, Gregory W, et al. Metabolic polymorphisms. Pharmacol Ther.1993; 57(2-3): 129-60. PMID: 8361990

3. Goldstein JA, de Morais SM. Biochemistry and molecular biology of the human CYP2C subfamily. Pharmacogenetics.1994; 4: 285-99. PMID: 7704034

4. Bertilsson L, Dahl ML, Dalen P, et al. Molecular genetics of CYP2D6: clinical relevance with focus on psychotropic drugs.Br J Clin Pharmacol.2002; 53(2): 111-22. PMID: 11851634

5. Arvanitidis K, Ragia G, Iordanidou M, et al. Genetic polymorphisms of drug-metabolizing enzymes CYP2D6, CYP2C9, CYP2C19 and CYP3A5 in the Greek population. Fundam Clin Pharmacol. 2007; 21(4): 419-26. PMID: 17635181

6. De Morais SM, Wilkinson GR, Blaisdell J, et al. Identification of a new genetic defect responsible for the polymorphism of (S)mephenytoin metabolism in Japanese. Mol Pharmacol. 1994b; 46(4): 594-8. PMID: 7969038

7. Allabi AC, Gala JL, Desager JP, et al. Genetic polymorphisms of $\mathrm{CYP} 2 \mathrm{C} 9$ and $\mathrm{CYP} 2 \mathrm{C} 19$ in the Beninese and Belgian populations. Br J Clin Pharmacol 2003; 56(6): 653-7. PMID: 14616425

8. Goldstein JA, Ishizaki T, Chiba $\mathrm{K}$, et al. Frequencies of the defective CYP2C19 alleles responsible for the mephenytoin poor metabolizer phenotype in various Oriental, Caucasian, Saudi Arabian and American black populations.Pharmacogenetics.1997; 7(1): 59-64. PMID: 9110363

9. Ozawa S, Soyama A, Saeki M, et al. Ethnic differences in genetic polymorphisms of CYP2D6, CYP2C19, CYP3As and MDR1/ABCB1. Drug Metab Pharmacokinet. 2004; 19(2): 83-95. PMID: 15499174

10. Aynacioglu AS, Sachse C, Bozkurt A, et al. Low frequency of defective alleles of cytochrome P450 enzymes 2C19 and 2D6 in the Turkish population. Clin Pharmacol Ther.1999; 66(2): 185-92. PMID: 10460072

11. Nakamura K, Goto F, Ray WA, et al. Interethnic differences in genetic polymorphism of debrisoquin and mephenytoin hydroxylation between Japanese and Caucasian populations. Clin Pharmacol Ther.1985; 38(4): 402-8. PMID: 4042523

12. Herrlin K, Massele AY, Jande M, et al. Bantu Tanzanians have a decreased capacity to metabolize omeprazole and mephenytoin in relation to their CYP2C19 genotype. Clin Pharmacol Ther.1998; 64(4): 391-401. PMID: 9797796

13. Kubota $\mathrm{T}$, Chiba $\mathrm{K}$ and Ishizaki $\mathrm{T}$. Genotyping of Smephenytoin 4'-hydroxylation in an extended Japanese population. Clin Pharmacol Ther.1996; 60(6): 661-6. PMID: 8988068

14. de Morais SM, Goldstein JA, Xie HG, et al. Genetic analysis of the S-mephenytoin polymorphism in a Chinese population. Clin Pharmacol Ther.1995; 58(4): 404-11. PMID: 7586932

15. Tassaneeyakul W, Tawalee A, Tassaneeyakul W, et al Analysis of the CYP2C19 polymorphism in a North-eastern Thai population. Pharmacogenetics.2002; 12(3): 221-5. PMID: 11927837

16. Zand N, Tajik N, Moghaddam AS, et al. Genetic polymorphisms of cytochrome P450 enzymes 2C9 and 2C19 in a healthy Iranian population. Clin Exp Pharmacol Physiol. 2007; 34(1-2): 102-5. PMID: 17201743

17. Azarpira N, Namazi S, Hendijani $\mathrm{F}$, et al. Investigation of allele and genotype frequencies of CYP2C9, CYP2C19 and VKORC1 in Iran. Pharmacol Rep. 2010; 62(4): 740-6. PMID: 20885015

18. Hashemi Soteh M, Peake IR, Marsden L, et al. Mutational analysis of the von Willebrand factor gene in type 1 von Willebrand disease using conformation sensitive gel electrophoresis: a comparison of fluorescent and manual techniques. Haematologica. 2007; 92(4): 550-3. PMID: 17488667

19. de Morais SM, Wilkinson GR, Blaisdell J, et al.The major genetic defect responsible for the polymorphism of S-mephenytoin metabolism in humans. J Biol Chem. 1994a; 269(22): 15419-22. PMID: 8195181

20. Adithan C, Gerard N, Vasu S, et al. Allele and genotype frequency of $\mathrm{CYP} 2 \mathrm{C} 19$ in a Tamilian population. $\mathrm{Br} \mathrm{J}$ Clin Pharmacol. 2003; 56(3): 331-3. PMID: 12919183

21. Bozina N, Granic P, Lalic Z, et al. Genetic polymorphisms of cytochromes P450: CYP2C9, CYP2C19, and CYP2D6 in Croatian population. Croat Med J. 2003; 44(4): 425-8. PMID: 12950145

22. Herman D, Dolzan V and Breskvar K. Genetic polymorphism of cytochromes P450 2C9 and 2C19 in Slovenian population. Zdravniski Vestink. 2003; 72(6): 347-52.

23. Scordo MG, Caputi AP, D'Arrigo C, et al. Allele and genotype frequencies of CYP2C9, CYP2C19 and CYP2D6 in an Italian population. Pharmacol Res. 2004; 50(2): 195-200. PMID: 15177309

24. Gaikovitch EA, Cascorbi I, Mrozikiewicz PM, et al. Polymorphisms of drug-metabolizing enzymes CYP2C9, CYP2C19, CYP2D6, CYP1A1, NAT2 and of P-glycoprotein in a Russian population. Eur J Clin Pharmacol. 2003; 59(4): 303-12. PMID: 12879168

25. Jose R, Chandrasekaran A, Sam SS, et al. CYP2C9 and CYP2C19 genetic polymorphisms: frequencies in the south Indian population. Fundam Clin Pharmacol.2005; 19(1): 101-5. PMID: 15660966

26. Bathum L, Skjelbo E, Mutabingwa TK, et al. Phenotypes and genotypes for CYP2D6 and CYP2C19 in a black Tanzanian population. Br J Clin Pharmacol.1999; 48(3): 395-401. PMID: PMID: 10510152

27. Hamdy SI, Hiratsuka M, Narahara K, et al. Allele and genotype frequencies of polymorphic cytochromes P450 (CYP2C9, CYP2C19, CYP2E1) and dihydropyrimidine dehydrogenase (DPYD) in the Egyptian population. Br J Clin Pharmacol.2002; 53(6): 596-603. PMID: 12047484

28. Allabi AC, Gala JL and Horsmans Y. CYP2C9, CYP2C19, ABCB1 (MDR1) genetic polymorphisms and phenytoin metabolism in a Black Beninese population. Pharmacogenet Genomics.2005; 15(11): 779-86. PMID: 16220110 
29. Persson I, Aklillu E, Rodrigues F, et al. S-mephenytoin hydroxylation phenotype and CYP2C19 genotype among Ethiopians. Pharmacogenetics.1996; 6(6): 521-6. PMID: 9014201

30. Zendehdel N, Biramijamal F, Hossein-Nezhad A, et al. Role of cytochrome $\mathrm{P} 4502 \mathrm{C} 19$ genetic polymorphisms in the therapeutic efficacy of omeprazole in Iranian patients with erosive reflux esophagitis. Arch Iran Med. 2010; 13(5): 406-12. PMID: 20804307

31. Stine SM, Southwick SM, Petrakis IL, et al. Yohimbineinduced withdrawal and anxiety symptoms in opioid-dependent patients. Biol Psychiatry.2002; 51(8): 642-51. PMID: 11955464
32. Sameer AE, Amany GM, Abdela AA, et al. CYP2C19 genotypes in a population of healthy volunteers and in children with hematological malignancies in Gaza Strip. Can J Clin Pharmacol. 2009; 16(1): e156-62. PMID: 19193970

33. Jurima-Romet M, Goldstein JA, LeBelle M, et al. CYP2C19 genotyping and associated mephenytoin hydroxylation polymorphism in a Canadian Inuit population. Pharmacogenetics.1996; 6(4): 329-39. PMID: 8873219

34. Lamba JK, Dhiman RK and Kohli KK.CYP2C19 genetic mutations in North Indians. Clin Pharmacol Ther.2000; 68(3): 328. PMID: 11014415 